\title{
A SUPPORT VECTOR MACHINE METHOD FOR BID/NO BID DECISION MAKING
}

\author{
Rifat SONMEZ ${ }^{\mathrm{a}}$, Burak SÖZGEN ${ }^{\mathrm{b}}$ \\ a Department of Civil Engineering, Middle East Technical University, Ankara, 06800 Turkey \\ ${ }^{b}$ Heerema Fabrication Group, Rotterdam Area, Netherlands
}

Received 28 Jan 2016; accepted 18 Aug 2016

\begin{abstract}
The bid/no bid decision is an important and complex process, and is impacted by numerous variables that are related to the contractor, project, client, competitors, tender and market conditions. Despite the complexity of bid decision making process, in the construction industry the majority of bid/no bid decisions is made informally based on experience, judgment, and perception. In this paper, a procedure based on support vector machines and backward elimination regression is presented for improving the existing bid decision making methods. The method takes advantage of the strong generalization properties of support vector machines and attempts to further enhance generalization performance by eliminating insignificant input variables. The method is implemented for bid/no bid decision making of offshore oil and gas platform fabrication projects to achieve a parsimonious support vector machine classifier. The performance of the support vector machine classifier is compared with the performances of the worth evaluation model, linear regression, and neural network classifiers. The results show that the support vector machine classifier outperforms existing methods significantly, and the proposed procedure provides a powerful tool for bid/no bid decision making. The results also reveal that elimination of the insignificant input variables improves generalization performance of the support vector machines.
\end{abstract}

Keywords: construction management, support vector machine, bidding, decision making, decision support systems, classification, machine learning.

\section{Introduction}

In the construction industry, the majority of the contractors is awarded new projects through the bidding process. Since bidding for a project requires a commitment of time and resources, the decision to bid or not bid on a project is one of the most important bidding decisions so that limited company resources are allocated effectively. Bidding on an inappropriate project can lead to wasted time and resources, whereas not bidding on an appropriate project may result in loss of business opportunities, such as profit, experience, and long-term relationship with a new client (Wanous et al. 2003). The decision to bid or not bid is made based on numerous factors that are related to the contractor, project, client, competitors, tender and market conditions (Ahmad, Minkarah 1988; Shash 1993). Despite the complexity of bid decision making process, the majority of the contractors makes the bid/no bid decision informally based on experience, judgment, and perception (Ahmad, Minkarah 1988). In recent years few research has focused on developing alternative methods to improve the bid/no bid decision making process.

Ahmad (1990) presented a structured methodology for the bid/no bid decision problem for construction projects. The methodology consisted of a deterministic worth-evaluation model in which the individual worths on the factors are weighted and combined to obtain an overall score, based on subjective evaluation of the bid/ no bid factors (Ahmad 1990). The deterministic worthevaluation methodology was illustrated by using a hypothetical bid decision making scenario. In another early attempt to achieve a structured methodology for bidding decisions, Dawood (1995) suggested a framework that integrates expert systems and information systems for bid/no bid and mark-up decisions. Wanous et al. (2000) proposed a parametric approach, and a neural network model (Wanous et al. 2003) for the bid/no bid decision problem. The methods were validated using the train and test method and a sample of real-life bidding situations provided by contractors operating in Syria. Lin and Chen (2004) presented a fuzzy linguistic approach to support the decision to bid or not bid. The fuzzy linguistic approach was used to evaluate a bid opportunity of an international airplane project in Taiwan.

Egemen and Mohamed (2008) developed a knowledge-based system based on comprehensive surveys to

Corresponding author: Rifat Sonmez

E-mail: rsonmez@metu.edu.tr 
assist the contractors in bid/no bid and mark-up size decisions. The system was validated by comparing the system's decisions with the decisions of the experts. El-Mashaleh (2010) presented a data envelopment analysis approach which was based on non-parametric linear programming. Ravanshadnia et al. (2010) developed a multistage fuzzy multi-attribute decision making method. The method considered the portfolio effect for bid/ no bid decisions making. Cheng et al. (2011) presented a multi-criteria prospect model for bidding decisions. El-Mashaleh (2013) proposed an empirical framework for making the bid/no-bid decisions.

The literature includes few research that present alternative methods for the bid/no bid decision making. However, there has been very little focus on development of methods employing support vector machines, despite the success of these methods for classification problems that are similar to the bid/no bid decision making problem. The main objective of this research is to improve the existing $\mathrm{bid} / \mathrm{no}$ bid decision classification methods by presenting a procedure based on support vector machines. The paper also aims to improve generalization performance of support vector machines by integrating backward elimination regression technique in variable selection.

\section{Bidding process in offshore oil and gas platform fabrication projects}

The duration of bid preparation and the amount of resources committed for bidding varies among different project types. Offshore oil and gas platform fabrication projects are among the projects that require a detailed evaluation and preparation period. The bidding process includes preparation of the tender plan, preparation of the fabrication plan, collection of quotations for the materials, quality, safety and environmental check, preparation of the price matrix schedule showing quantities and manhours per discipline, risk assessment of the tender, and preparation of the final cost estimate. Bidding for the offshore petroleum platform fabrication projects is performed by the cooperation of multi-disciplinary parties, including structural, mechanical, piping, electrical, and instrumentation departments. This complicated bid preparation period inevitably involves a considerable amount of expense for the fabrication company. The total cost of bid preparation of tender varies according to the contract type. For EPC (Engineering, Procurement, and Construction) and EPIC (Engineering, Procurement, Installation and Commissioning) types of contracts the bid preparation cost varies between $€ 500.000-€ 1.000 .000$ if detailed pre-engineering work is available. Hence the bid/no bid decision making is very crucial for the offshore oil and gas platform fabrication projects.

\section{Support vector machines}

The Support Vector Machine (SVM) is a non-probabilistic supervised classification method derived from statistical learning theory. The SVM maps the input vectors into a high-dimensional feature space using a priori selected kernel function to separate the classes with a decision surface called the optimal hyperplane. Special properties of the decision surface enable high generalization ability (Cortes, Vapnik 1995).

The optimal separating hyperplane is a decision function that has the maximal margin between the vectors of classes. The margin is determined by the small portion of the training data called "support vectors" which are used to construct the optimal hyperplane. It was shown that if the optimal hyperplane can be constructed with a small number of support vectors relative to the training set size the generalization ability of SVM will be high (Cortes, Vapnik 1995). For a two-class classification problem with $L$ training points, where each input $x_{i}$ is in one of two classes $y_{i}=-1$ or +1 , the training set is of the form:

$$
\left(y_{1}, \mathrm{x}_{1}\right), \ldots\left(y_{l}, \mathrm{x}_{l}\right), y_{i}\{-1,1\} .
$$

The optimal separating hyperplane can be determined by solving the following optimization problem (Cortes, Vapnik 1995):

$$
\min \frac{1}{2} w^{2}+C \sum_{i=1}^{l} \xi_{i}
$$

$$
\text { subject to: } y_{i}\left(w \cdot \varphi\left(x_{i}\right)+b\right) \geq 1-\xi_{i} \text {; }
$$

$$
\xi_{i} \geq 0
$$

The vector $\mathrm{w}$ and the scalar $b$ define separating hyperplane's optimal orientation. The slack variables $\xi_{i}$ are used to allow non-separable training data. $C$ is the penalty parameter and determines the relative importance of maximizing the margin and minimizing the amount of slack. For data that is not linearly separable, the kernel $\varphi$ is used for mapping the input vector $\mathrm{x}$ to a higher dimensional feature space as follows:

$$
K\left(x, x_{i}\right)=\varphi(x) \cdot \varphi\left(x_{i}\right) .
$$

$K\left(x, x_{i}\right)$ is a priori decided function satisfying Mercer's condition (Vapnik 2000). Learning machines with different types of nonlinear decision surfaces in input space can be constructed by using different kernels. Polynomial learning machines, radial basis functions machines, and sigmoid (two-layer neural networks) are among the most commonly studied learning machines with nonlinear decision surfaces. Radial basis function (Gaussian) is in the following form:

$$
K\left(x, x_{i}\right)=\exp \left(-\frac{\left|x-x_{i}\right|^{2}}{2 \sigma^{2}}\right)
$$

in which $\mathrm{s}>0$ is a kernel parameter. 
Support vector machines have been successfully applied to many real world classification problems. Examples of support vector machines in construction management include: contractor prequalification decision (Lam et al. 2009), project success prediction (Cheng et al. 2010), contractor default prediction (Tserng et al. 2011), cash flow prediction (Cheng, Roy 2011; Cheng et al. 2015a), project at completion estimation (Cheng, Roy 2010; Cheng et al. 2012; Cheng, Hoang 2014a), conceptual cost estimation (Cheng, Roy 2010), litigation outcome prediction (Mahfouz, Kandil 2012), enterprise resource planning software effort forecasting (Chou et al. 2012), dispute prediction (Chou 2012; Chou, Lin 2012; Chou et al. 2013, 2014), construction cost index estimation (Cheng et al. 2013), contractor default prediction (Cheng et al. 2014), bridge-maintenance risk score prediction (Cheng, Hoang 2014b), change order productivity loss prediction (Cheng et al. 2015b). Despite the success of support vector machines in different construction management related classification problems, to the best of our knowledge, application of these methods have not been explored for bid/no bid decision making, which is the main focus of this study.

\section{Bid/no bid decision classifiers}

In this section first the existing bid/no bid methods that are used to evaluate performance of the proposed support vector machine are explained along with the novel support vector machine procedure. The proposed procedure is then implemented to construct a support vector machine classifier for bid/no bid decision making in offshore oil and gas platform fabrication projects. Actual bidding data of a company that is specialized in the engineering and fabrication of offshore oil and gas structures are used as the training data. The bidding data of the company included information of eight variables impacting the bid/ no bid decisions, and outcome of bids for 40 oil and gas platform fabrication projects. Along the with support vector machine classifier, linear regression, and feed-forward neural network classifiers are developed to evaluate prediction performance of the support vector machine classifier. The worth evaluation model of the offshore oil and gas company is also included in the comparisons.

\subsection{Worth-evaluation classifier}

The offshore oil and gas company that has provided the data for this research have developed a worth evaluation classifier for bid/no bid decision making. The worth evaluation classifier is very similar to the worth evaluation model proposed by Ahmad (1990) in which the individual worths of the variables are weighted and combined to obtain an overall score, based on subjective evaluation of the bid/no bid variables. The variables impacting the bid/ no bid decisions, and the weights of the variables were determined by a team consisting of senior level commercial and project managers within the company, who have significant tender preparation experience. The team used eight variables for bid/no bid decision making. These variables are presented in Table 1. As there are numerous factors that effect bid/no bid decisions, eight variables represent only a limited set of factors impacting bid/no bid decisions. However, these eight variables were the major factors considered by the commercial and project managers in bid/no bid decisions. A five point scale is used for subjective evaluation of the bid/no bid variables. The values of eight variables for the 40 projects, along with the actual bid/no bid decisions are included in Table 2. The worth evaluation model determines the probability of winning the bid by considering the subjective evaluation of the variables and pre-determined variable weights. The bid/no bid classifications of the worth evaluation model for 40 projects are compared with the actual bid outcomes to evaluate the performance of this classifier. The worth evaluation model classified $19 \mathrm{bid} / \mathrm{no}$ bid decisions correctly and achieved a success rate of $47.5 \%$ (Sözgen 2009).

Table 1. Variables impacting bid/no bid decision

\begin{tabular}{cl}
\hline ID & \multicolumn{1}{c}{ Description } \\
\hline$x_{1}$ & Scope Fit \\
$x_{2}$ & Political Position \\
$x_{3}$ & Safety Appreciation \\
$x_{4}$ & Track Record \\
$x_{5}$ & Personal Relation \\
$x_{6}$ & Yard Location \\
$x_{7}$ & Know-How \\
$x_{8}$ & Ultimate Price Level \\
\hline
\end{tabular}

\subsection{Linear regression classifier}

Linear regression analysis enables development of parsimonious classifiers including few parameters. In this research linear regression analysis is not only used to evaluate performance of support vector classifiers, but also to assist variable selection in neural networks and support vector machines. The first linear regression model (RM1) included all of the candidate variables that may impact the $\mathrm{bid} / \mathrm{no}$ bid decisions, and was in the following form:

$$
\begin{aligned}
y= & \beta_{0}+\beta_{1} x_{1}+\beta_{2} x_{2}+\beta_{3} x_{3}+\beta_{4} x_{4}+ \\
& \beta_{5} x_{5}+\beta_{6} x_{6}+\beta_{7} x_{7}+\beta_{8} x_{8}
\end{aligned}
$$

in which $y$ is the probability of winning the bid, $x_{1}, x_{2}$, $\ldots, x_{8}$ are the independent variables impacting bid/no bid decision making, and $\beta_{0}, \beta_{1}, \ldots, \beta_{8}$ are the regression coefficients. Similar to the worth-evaluation classifier, if $y$ $<0.5$ the regression classifier suggests not to bid, whereas if $y \geq 0.5$ the classifier suggests to bid.

The candidate variables that did not have a significant impact on the probability of winning the bid are dropped from the model, one at a time, by backward elimination technique to achieve a parsimonious regression model. The variables that had a regression coefficient that is not significant at a 0.2 significance level ( $p$-value) 
Table 2. Bidding data

\begin{tabular}{|c|c|c|c|c|c|c|c|c|c|}
\hline $\begin{array}{c}\text { Project } \\
\text { No }\end{array}$ & $x_{1}$ & $x_{2}$ & $x_{3}$ & $x_{4}$ & $x_{5}$ & $x_{6}$ & $x_{7}$ & $x_{8}$ & $\begin{array}{c}\mathrm{Bid} / \mathrm{No} \\
\mathrm{Bid}\end{array}$ \\
\hline 1 & 5 & 3 & 3 & 5 & 4 & 4 & 5 & 3 & 1 \\
\hline 2 & 4 & 3 & 3 & 4 & 3 & 3 & 4 & 2 & 0 \\
\hline 3 & 4 & 2 & 3 & 3 & 4 & 3 & 3 & 4 & 0 \\
\hline 4 & 5 & 5 & 3 & 5 & 5 & 5 & 3 & 2 & 1 \\
\hline 5 & 3 & 2 & 3 & 3 & 3 & 4 & 3 & 2 & 0 \\
\hline 6 & 3 & 2 & 3 & 3 & 4 & 3 & 3 & 3 & 0 \\
\hline 7 & 3 & 2 & 3 & 2 & 2 & 4 & 2 & 3 & 0 \\
\hline 8 & 5 & 2 & 3 & 4 & 5 & 4 & 4 & 3 & 1 \\
\hline 9 & 5 & 3 & 3 & 5 & 5 & 3 & 4 & 3 & 1 \\
\hline 10 & 2 & 2 & 3 & 3 & 4 & 3 & 3 & 3 & 0 \\
\hline 11 & 5 & 2 & 3 & 4 & 5 & 3 & 3 & 3 & 1 \\
\hline 12 & 3 & 3 & 3 & 3 & 2 & 1 & 4 & 2 & 0 \\
\hline 13 & 3 & 4 & 2 & 2 & 2 & 2 & 4 & 1 & 0 \\
\hline 14 & 4 & 4 & 3 & 3 & 4 & 4 & 3 & 3 & 1 \\
\hline 15 & 2 & 3 & 3 & 2 & 3 & 3 & 2 & 2 & 0 \\
\hline 16 & 1 & 3 & 3 & 3 & 3 & 3 & 3 & 2 & 0 \\
\hline 17 & 2 & 2 & 3 & 2 & 1 & 3 & 2 & 2 & 0 \\
\hline 18 & 2 & 2 & 3 & 2 & 2 & 2 & 2 & 3 & 0 \\
\hline 19 & 2 & 3 & 3 & 5 & 4 & 5 & 4 & 4 & 1 \\
\hline 20 & 2 & 1 & 3 & 2 & 2 & 2 & 2 & 3 & 0 \\
\hline 21 & 5 & 4 & 3 & 4 & 5 & 5 & 5 & 5 & 0 \\
\hline 22 & 5 & 4 & 4 & 5 & 4 & 5 & 4 & 3 & 0 \\
\hline 23 & 2 & 3 & 3 & 5 & 4 & 5 & 4 & 4 & 1 \\
\hline 24 & 5 & 3 & 3 & 5 & 5 & 3 & 4 & 3 & 0 \\
\hline 25 & 4 & 4 & 3 & 2 & 4 & 5 & 3 & 3 & 0 \\
\hline 26 & 3 & 2 & 3 & 3 & 4 & 2 & 4 & 4 & 1 \\
\hline 27 & 4 & 2 & 3 & 5 & 4 & 3 & 3 & 3 & 0 \\
\hline 28 & 4 & 5 & 3 & 3 & 4 & 3 & 4 & 1 & 0 \\
\hline 29 & 4 & 2 & 3 & 5 & 3 & 3 & 3 & 3 & 0 \\
\hline 30 & 4 & 3 & 3 & 3 & 3 & 3 & 3 & 3 & 0 \\
\hline 31 & 3 & 2 & 3 & 3 & 4 & 3 & 4 & 3 & 0 \\
\hline 32 & 3 & 4 & 3 & 2 & 4 & 3 & 2 & 3 & 1 \\
\hline 33 & 3 & 3 & 3 & 3 & 4 & 3 & 3 & 3 & 0 \\
\hline 34 & 3 & 2 & 3 & 3 & 3 & 3 & 3 & 3 & 0 \\
\hline 35 & 2 & 4 & 3 & 2 & 5 & 2 & 2 & 3 & 1 \\
\hline 36 & 4 & 2 & 3 & 3 & 3 & 1 & 3 & 3 & 0 \\
\hline 37 & 3 & 3 & 3 & 2 & 2 & 3 & 3 & 3 & 0 \\
\hline 38 & 2 & 3 & 3 & 2 & 2 & 2 & 3 & 1 & 0 \\
\hline 39 & 2 & 2 & 3 & 3 & 2 & 2 & 2 & 1 & 0 \\
\hline 40 & 1 & 4 & 3 & 2 & 5 & 3 & 2 & 3 & 1 \\
\hline
\end{tabular}

are eliminated one at a time. Hence, the independent variables $x_{2}, x_{3}, x_{4}, x_{6}, x_{7}, x_{8}$ are eliminated respectively as shown in Table 3, and the linear regression classifier included the variables $x_{1}$ and $x_{5}$.

Ten-fold cross-validation technique is used to evaluate performance of the linear regression classifier. The data set is divided into 10 subsets, each containing data of four projects. The bid/no bid decision for each subset is determined by the regression models that are developed based on the 36 project data which excluded the 4 project data of the each subset being evaluated. The results of ten-fold cross-validation revealed that the final regression model classified $32 \mathrm{bid} / \mathrm{no}$ bid decisions correctly and achieved a success rate of $80.0 \%$.

Table 3. Variable selection procedure for the linear regression model

\begin{tabular}{l|l|l|l}
\hline Model & \multicolumn{1}{|c|}{ Independent variables } & $\begin{array}{c}\text { Variable } \\
\text { eliminated }\end{array}$ & $p$-value \\
\hline RM1 & $x_{1}, x_{2}, x_{3}, x_{4}, x_{5}, x_{6}, x_{7}, x_{8}$ & $x_{6}$ & 0.924 \\
RM2 & $x_{1}, x_{2}, x_{3}, x_{4}, x_{5}, x_{7}, x_{8}$ & $x_{8}$ & 0.411 \\
RM3 & $x_{1}, x_{2}, x_{3}, x_{4}, x_{5}, x_{7}$ & $x_{2}$ & 0.420 \\
RM4 & $x_{1}, x_{3}, x_{4}, x_{5}, x_{7}$ & $x_{7}$ & 0.468 \\
RM5 & $x_{1}, x_{3}, x_{4}, x_{5}$ & $x_{4}$ & 0.408 \\
RM6 & $x_{1}, x_{3}, x_{5}$ & $x_{3}$ & 0.433 \\
RM7 & $x_{1}, x_{5}$ & & 0.208 \\
\hline
\end{tabular}

\subsection{Neural network classifier}

Linear regression classifier considers only linear relations which does not always guarantee an adequate representation of the relations. Hence, a neural network classifier is also developed for establishing an alternative mapping function to evaluate the performance of the proposed support vector machines. The neural network classifer consisted of a one hidden layer feed forward neural network model with a sigmoid transfer function. Backpropagation algorithm is used to train the neural networks.

Elimination of input variables that do not have a significant impact on the bid/no bid decisions are considered in neural network modeling, since elimination of the unimportant input variables may improve generalization capabilities of neural networks (Shastri et al. 1998; Sonmez 2011). In the initial neural network model (NN1) all of the eight candidate variables are included in the input layer as shown in Figure 1. In neural network models the number hidden units is taken as the half of the sum of the number of input units and number of output units (Sonmez, Rowings 1998; Sonmez 2011). The performance of the first neural network is determined by implementing ten-fold cross-validation technique with the same 10 test subsets which were also used to determine the performance of the final regression model. The NN1 correctly classified 30 projects $(75.0 \%)$. The input variables of the neural network models are eliminated in the order that was used in the backward elimination regression method as shown in Table 4 . When the variable $x_{3}$ 


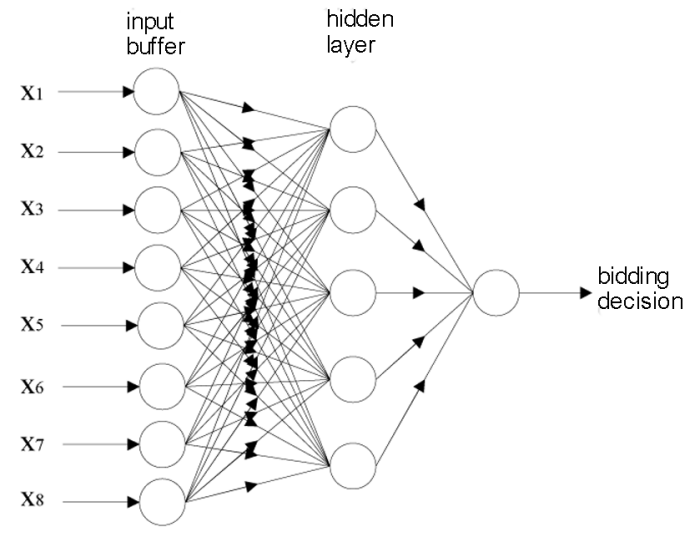

Fig. 1. Neural network classifier

is removed, the ten-fold cross-validation correct classification performance has decreased to $77.5 \%$ (NM7) from $80.0 \%$ (NN6). Hence the variable $x_{3}$ is included in the neural network classifier along with the variables $\mathrm{x}_{1}$ and $\mathrm{x}_{5}$ which were included in the linear regression classifier.

Table 4. Variable selection procedure for the neural network model

\begin{tabular}{l|l|c}
\hline Model & \multicolumn{1}{|c|}{ Independent variables } & \multicolumn{1}{|c}{$\begin{array}{c}\text { Correct } \\
\text { classification (\%) }\end{array}$} \\
\hline NN1 & $x_{1}, x_{2}, x_{3}, x_{4}, x_{5}, x_{6}, x_{7}, x_{8}$ & 75.0 \\
NN2 & $x_{1}, x_{2}, x_{3}, x_{4}, x_{5}, x_{7}, x_{8}$ & 75.0 \\
NN3 & $x_{1}, x_{2}, x_{3}, x_{4}, x_{5}, x_{7}$ & 77.5 \\
NN4 & $x_{1}, x_{3}, x_{4}, x_{5}, x_{7}$ & 77.5 \\
NN5 & $x_{1}, x_{3}, x_{4}, x_{5}$ & 77.5 \\
NN6 & $x_{1}, x_{3}, x_{5}$ & 80.0 \\
NN7 & $x_{1}, x_{5}$ & 77.5 \\
\hline
\end{tabular}

\subsection{Support vector machine classifier}

The novel support vector machine procedure for bid/no bid decision making considers the development of a parsimonious support vector machine (SVM) classifier by including only the significant variables impacting the bid/ no bid decisions. The procedure starts with constructing an initial support vector machine (SVM1) which includes all of the eight candidate variables as the input variables as shown in Figure 2. The support vector machines are developed in MATLAB 2014a by considering a radial

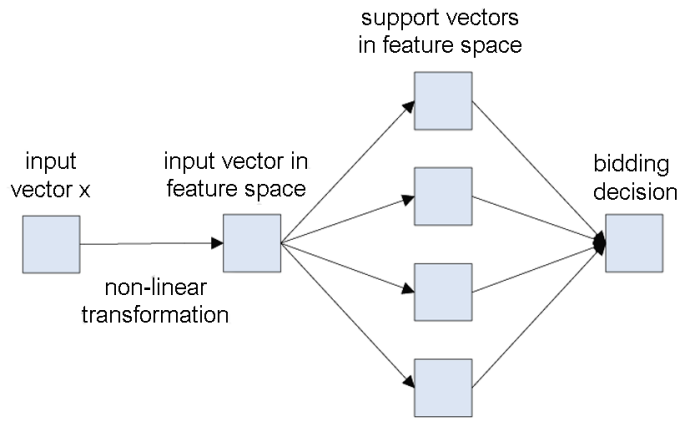

Fig. 2. Support vector machine classifier

basis function (Gaussian) kernel as shown in Figure 3. The radial basis kernel is considered as it includes fewer hyperparameters than the polynomial kernel (Hsu et al. 2003), and the linear support vector machine is a special case of radial basis function machines (Keerthi, Lin 2003). The default MATLAB 2014a values for the penalty parameter $C$ and kernel parameter s are used to construct the bid/no bid support vector machines.

To achieve a parsimonious support vector machine classifier the elimination of the input variables are considered according to the order defined by the backward elimination regression method (BER). The input variable which is being considered for elimination is not eliminated when the ten-fold cross-validation performance of the preceding support vector machine is better than the performance of the succeeding support vector machine. The variable selection procedure is summarized in $\mathrm{Ta}-$ ble 5. The first variable that was considered for elimination was $\mathrm{x}_{6}$ which was the first variable eliminated by the backward elimination regression method. This variable is eliminated as the ten-fold cross-validation correct classification performance of the succeeding support vector machine (SVM2) has improved to $82.5 \%$ from $80.0 \%$ (SVM1). The second and third variables that were considered for elimination were $x_{8}$ and $x_{2}$ respectively. These variables were not removed since elimination of these input variables decreased the ten-fold cross-validation correct classification performance. However, variable $x_{7}$ is removed since the performance of the SVM5 has improved to $85 \%$ by elimination of this variable. Similarly, the variable $x_{4}$ is also eliminated as SVM6 has achieved a cross-validation correct classification performance of

BID

BID

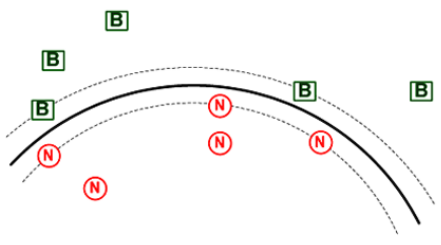

NO BID

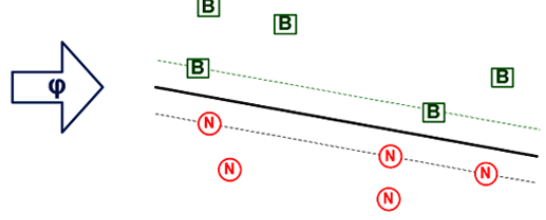

NO BID

Fig. 3. Illustration of the kernel transformation for bid/no bid SVMs 
$90.0 \%$. The last variable that was considered for elimination was $x_{3}$, which was the last variable eliminated by the backward elimination regression method. Elimination of $x_{3}$ has decreased the performance to $80.0 \%$ (SVM7), hence this variable was not eliminated. The backward elimination variable selection procedure which was presented in this research, improved the correct classification performance of bid/no bid support vectors from $80.0 \%$ (SVM1) to $90.0 \%$ (SVM6). The proposed bid/no bid decision making support vector machine procedure is summarized in Figure 4.
Table 5. Variable selection procedure for the support vector machine

\begin{tabular}{l|l|c}
\hline Model & \multicolumn{1}{|c|}{ Independent variables } & \multicolumn{1}{|c}{$\begin{array}{c}\text { Correct } \\
\text { classification (\%) }\end{array}$} \\
\hline SVM1 & $x_{1}, x_{2}, x_{3}, x_{4}, x_{5}, x_{6}, x_{7}, x_{8}$ & 80.0 \\
SVM2 & $x_{1}, x_{2}, x_{3}, x_{4}, x_{5}, x_{7}, x_{8}$ & 82.5 \\
SVM3 & $x_{1}, x_{2}, x_{3}, x_{4}, x_{5}, x_{7}$ & 80.0 \\
SVM4 & $x_{1}, x_{3}, x_{4}, x_{5}, x_{7}, x_{8}$ & 80.0 \\
SVM5 & $x_{1}, x_{2}, x_{3}, x_{4}, x_{5}, x_{8}$ & 85.0 \\
SVM6 & $x_{1}, x_{2}, x_{3}, x_{5}, x_{8}$ & 90.0 \\
SVM7 & $x_{1}, x_{2}, x_{5}, x_{8}$ & 80.0 \\
\hline
\end{tabular}

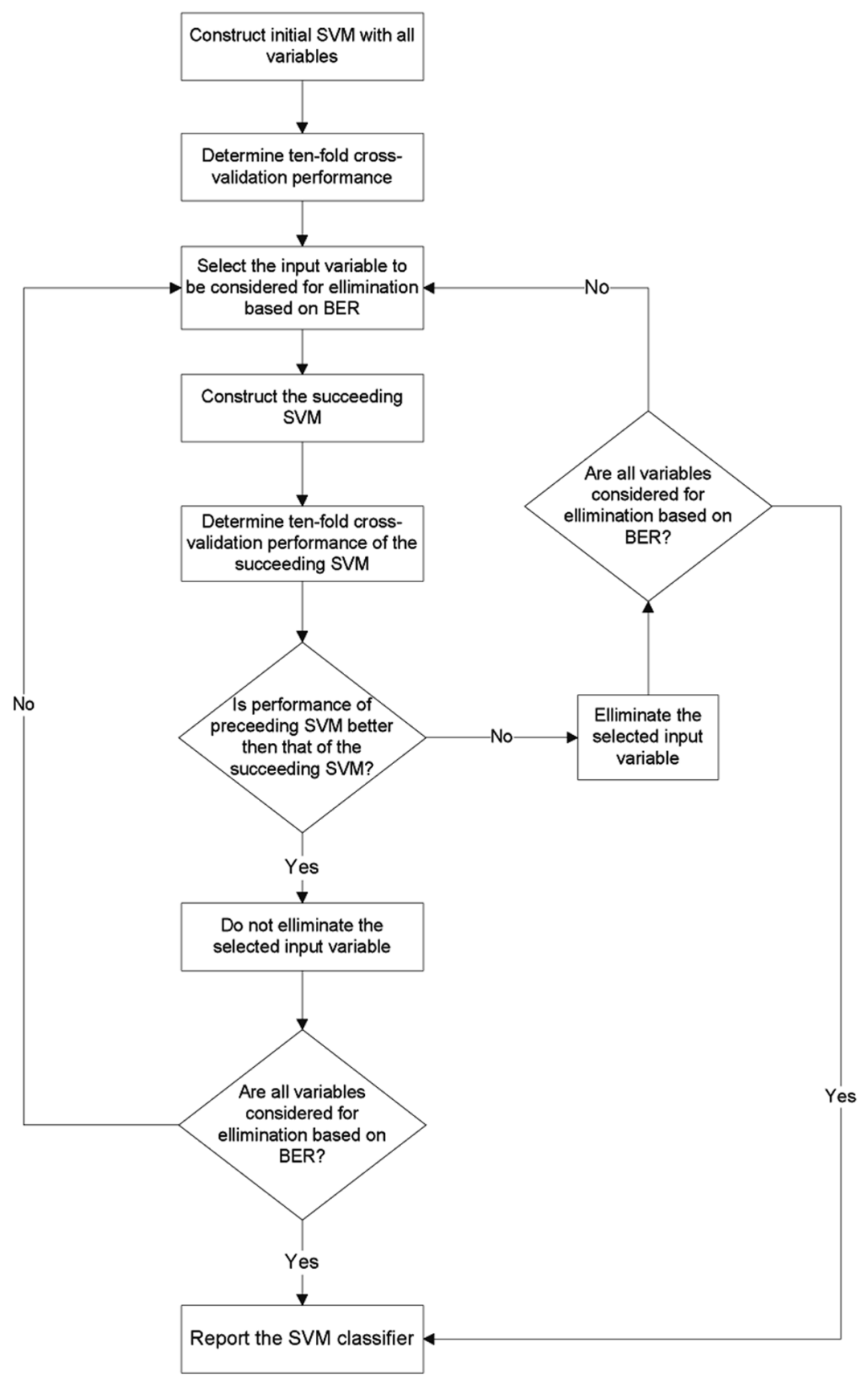

Fig. 4. Flow chart of the proposed support vector machine method 


\begin{tabular}{|l|c|c|}
\cline { 2 - 3 } \multicolumn{1}{c|}{} & \multicolumn{2}{c|}{ Predicted } \\
\hline Actual & Bid (+) & No Bid (-) \\
\hline Bid $(+)$ & 12 & 0 \\
\hline No Bid (-) & 21 & 7 \\
\hline
\end{tabular}

Worth-Evaluation Classifier (WEC)

\begin{tabular}{|l|c|c|}
\cline { 2 - 3 } \multicolumn{1}{c|}{} & \multicolumn{2}{c|}{ Predicted } \\
\hline Actual & Bid (+) & No Bid (-) \\
\hline Bid (+) & 6 & 6 \\
\hline No Bid (-) & 2 & 26 \\
\hline
\end{tabular}

Linear Regression Classifier (RM7)

\begin{tabular}{|l|c|c|}
\cline { 2 - 3 } \multicolumn{1}{c|}{} & \multicolumn{2}{c|}{ Predicted } \\
\hline Actual & Bid $(+)$ & No Bid (-) \\
\hline Bid $(+)$ & 6 & 6 \\
\hline No Bid $(-)$ & 2 & 26 \\
\hline
\end{tabular}

Neural Network Classifier (NN6)

\begin{tabular}{|l|c|c|}
\cline { 2 - 3 } \multicolumn{1}{c|}{} & \multicolumn{2}{c|}{ Predicted } \\
\hline Actual & Bid (+) & No Bid (-) \\
\hline Bid $(+)$ & 11 & 1 \\
\hline No Bid $(-)$ & 3 & 25 \\
\hline
\end{tabular}

Support Vector Machine Classifier (SVM6)

Fig. 5. Confusion matrices for bid/no bid classifiers

\subsection{Comparison of bid/no bid classifiers}

In machine learning, confusion matrices are commonly used to evaluate performance of the classifiers (Sammut, Webb 2011). A confusion matrix is used not only to determine the overall performance of a classifier, but also to reveal performances of the classifier for the different classes. The confusion matrices of the worth evaluation classifier (WEC), the linear regression classifier (RM7), neural network classifier (NN6), and the support vector machine classifier (SVM6) are summarized in Figure 5. The four outcomes of classification; true positives (TP), false positives (FP), true negatives (TN), and false negatives (FN) for positive (bid) and negative (no bid) classes are illustrated in Figure 6. Five classification performance metrics are calculated by using the confusion matrices. The accuracy measures overall classification performance and is equal to the correct classification percentage. The true positive rate $(\%)$, true negative rate $(\%)$, positive predictive value (\%), and negative predictive value (\%) metrics are calculated as follows:

$$
\begin{aligned}
& \text { True positive rate }(\%)=\left(\frac{\mathrm{TP}}{\mathrm{TP}+\mathrm{FN}}\right) 100 \\
& \text { True negative rate }(\%)=\left(\frac{\mathrm{TN}}{\mathrm{TN}+\mathrm{FP}}\right) 100
\end{aligned}
$$

$$
\text { Positive predictive value }(\%)=\left(\frac{\mathrm{TP}}{\mathrm{TP}+\mathrm{FP}}\right) 100 \text {; }
$$

$$
\text { Negative predictive value }(\%)=\left(\frac{\mathrm{TN}}{\mathrm{TN}+\mathrm{FN}}\right) 100 \text {. }
$$

Table 6. Performance of bid/no bid classifiers

\begin{tabular}{l|c|c|c|c}
\hline & WEC & RM7 & NN6 & SVM6 \\
\hline True positive rate (\%) & 100.0 & 50.0 & 50.0 & 91.7 \\
True negative rate (\%) & 25.0 & 92.9 & 92.9 & 89.3 \\
Positive predictive value (\%) & 36.4 & 75.0 & 75.0 & 78.6 \\
Negative predictive value (\%) & 100.0 & 81.3 & 81.3 & 96.2 \\
Accuracy (\%) & 47.5 & 80.0 & 80.0 & 90.0 \\
\hline
\end{tabular}

\begin{tabular}{|l|c|c|}
\cline { 2 - 3 } \multicolumn{1}{c|}{} & \multicolumn{2}{c|}{ Predicted Class } \\
\hline Actual Class & Positive $(+)$ & Negative $(-)$ \\
\hline Positive $(+)$ & TP & FN \\
\hline Negative (-) & FP & TN \\
\hline
\end{tabular}

Fig. 6. The outcomes of classification into positive and negative classes

The performance metrics of the classifiers are summarized in Table 6. The worth evaluation classifier (WEC) which achieved a $47.5 \%$ correct classification had the worst accuracy. The true negative rate (\%), and positive predictive value (\%) performances of the WEC were also very poor. The linear regression (RM7) and the neural network (NN6) classifiers had both achieved an accuracy of $80.0 \%$, and had both poor classification performances for the "to bid" class with a true positive rate of $50.0 \%$. The support vector machine classifier (SVM6) not only achieved an accuracy of $90.0 \%$, but also was successful for both of the classes. The support vector machine classifier had a true positive rate of $91.7 \%$ and had a true negative rate of $89.3 \%$.

Interval plots of classifiers $95 \%$ confidence interval for the mean accuracy are performed by Minitap 17 Statistical Software to reveal the consistency of the classifiers among cross validation sets. Figure 7 displays the $95 \%$ confidence intervals for the mean accuracy of classifiers for the ten cross validation sets. The $95 \%$ confidence interval for the mean accuracy of the worth evaluation classifier lied between $37.3 \%$ and $57.6 \%$. The $95 \%$ confidence interval for the mean accuracy of the regression and neural network classifies were same, and laid between $68.7 \%$ and $91.3 \%$. The $95 \%$ confidence interval for the mean accuracy of the support vector classifier lied between $80.8 \%$ and $99.2 \%$, indicating consistency and high accuracy for the SVM6 among cross validation sets. The results confirmed the effectiveness and robustness of the proposed support vector machine procedure for bid/ no bid decision making. The results of the support vector machine procedure are presented to the commercial and project managers of the offshore oil and gas company that has provided the data. The managers considered adopting 


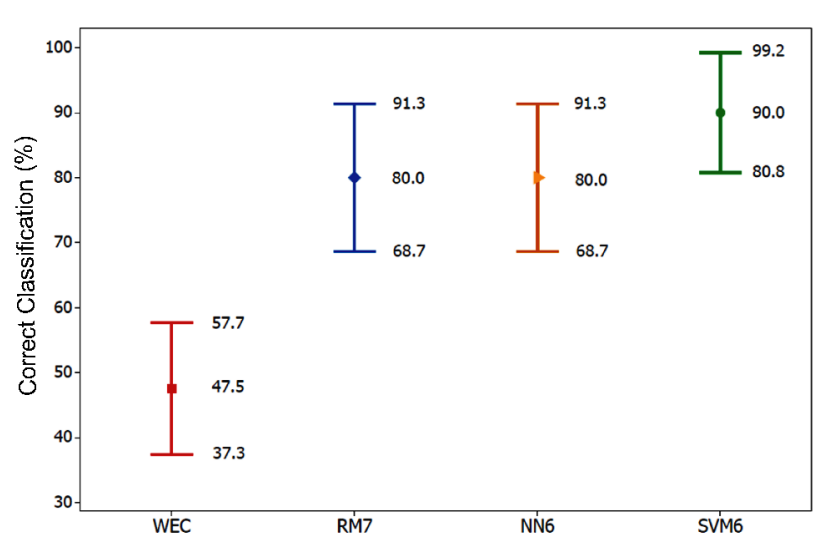

Fig. 7. Interval plot of classifiers $95 \%$ confidence intervals for the mean accuracy

the proposed procedure as a decision support system during no/bid decisions. The managers also recommended a dynamic procedure that enables adding new variables.

\subsection{Sensitivity analysis}

Sensitivity analysis was performed to determine the impact of the variables on the bid/no bid decision for SVM6. In sensitivity analysis, the values of one variable were increased from "one" to "five", at an increment of one, while those of the remaining variables were kept constant at value "three". The results of the sensitivity analysis are summarized in Table 7. The results indicate that the bid/ no bid decision is most sensitive to the variables Political Position $\left(x_{2}\right)$ and Ultimate Price Level $\left(x_{8}\right)$ followed by the variables Scope Fit $\left(x_{1}\right)$ and Personal Relation $\left(x_{5}\right)$.

Table 7. Sensitivity analysis results

\begin{tabular}{cccccc}
\hline Value & $x_{1}$ & $x_{2}$ & $x_{3}$ & $x_{5}$ & $x_{8}$ \\
\hline 1 & 0 & 0 & 0 & 0 & 0 \\
2 & 0 & 0 & 0 & 0 & 0 \\
3 & 0 & 0 & 0 & 0 & 0 \\
4 & 0 & 1 & 0 & 0 & 1 \\
5 & 1 & 1 & 0 & 1 & 1 \\
\hline
\end{tabular}

\section{Conclusions}

In this paper a procedure based on support vector machines and backward elimination regression method is presented for bid/no bid decision making. The procedure was successfully implemented for offshore oil and gas platform fabrication projects. The cross-validation performance results revealed that the support vector machine procedure outperformed existing bid/no bid decision methods. The support vector classifier achieved a significantly better performance than the worth evaluation classifier, linear regression classifier, and the neural network classifier in correct classification of bid/no bid decisions. The results indicate that the proposed procedure provides a powerful tool for bid/no bid decision making.

In the novel support vector machine procedure presented, a parsimonious support vector machine classifier is constructed by eliminating the insignificant input variables that are not contributing to the classifier. Backward elimination regression method is used along with cross validation to identify the insignificant input variables. The performance comparisons revealed that elimination of the insignificant input variables improved classification performance of the support vector machines. Although the input variable selection procedure presented for support vector machines is applied to bid/no bid decision making problem in this research, it can be adapted to other classification problems to achieve parsimonious support vector machines with improved generalization capabilities. The proposed procedure was applied to a limited data set including only eight variables. Future research, including larger data sets and additional variables will help to improve the understanding of bid/no bid decisions.

\section{References}

Ahmad, I. 1990. Decision-support system for modeling bid/nobid decision problem, Journal of Construction Engineering and Management 116(4): 595-608.

https://doi.org/10.1061/(ASCE)0733-9364(1990)116:4(595)

Ahmad, I.; Minkarah, I. 1988. Questionnaire survey on bidding in construction, Journal of Management in Engineering 4(3): 229-243. https://doi.org/10.1061/(ASCE)9742-597X(1988)4:3(229)

Cheng, M. Y.; Hoang, N. D. 2014a. Interval estimation of construction cost at completion using least squares support vector machine, Journal of Civil Engineering and Management 20(2): 223-236. https://doi.org/10.3846/13923730.2013.801891

Cheng, M. Y.; Hoang, N. D. 2014b. Risk score inference for bridge maintenance project using evolutionary fuzzy least squares support vector machine, Journal of Computing in Civil Engineering 28(3), 04014003. https://doi.org/10.1061/(ASCE)CP.1943-5487.0000275

Cheng, M. Y.; Roy, A. F. 2010. Evolutionary fuzzy decision model for construction management using support vector machine, Expert Systems with Applications 37(8): 60616069. https://doi.org/10.1016/j.eswa.2010.02.120

Cheng, M. Y.; Roy, A. F. 2011. Evolutionary fuzzy decision model for cash flow prediction using time-dependent support vector machines, International Journal of Project Management 29(1): 56-65.

https://doi.org/10.1016/j.ijproman.2010.01.004

Cheng, M. Y.; Wu, Y. W.; Wu, C. F. 2010. Project success prediction using an evolutionary support vector machine inference model, Automation in Construction 19(3): 302307. https://doi.org/10.1016/j.autcon.2009.12.003

Cheng, M. Y.; Hsiang, C. C.; Tsai, H. C.; Do, H. L. 2011. Bidding decision making for construction company using a multi-criteria prospect model, Journal of Civil Engineering and Management 17(3): 424-436. https://doi.org/10.3846/13923730.2011.598337

Cheng, M. Y.; Hoang, N. D.; Roy, A. F.; Wu, Y. W. 2012. A novel time-depended evolutionary fuzzy SVM inference model for estimating construction project at completion, Engineering Applications of Artificial Intelligence 25(4): 744-752. https://doi.org/10.1016/j.engappai.2011.09.022

Cheng, M. Y.; Hoang, N. D.; Wu, Y. W. 2013. Hybrid intelligence approach based on LS-SVM and differential evolution for construction cost index estimation: a Taiwan case study, Automation in Construction 35: 306-313. https://doi.org/10.1016/j.autcon.2013.05.018 
Cheng, M. Y.; Hoang, N. D.; Limanto, L.; Wu, Y. W. 2014. A novel hybrid intelligent approach for contractor default status prediction, Knowledge-Based Systems 71: 314-321. https://doi.org/10.1016/j.knosys.2014.08.009

Cheng, M. Y.; Hoang, N. D.; Wu, Y. W. 2015a. Cash flow prediction for construction project using a novel adaptive time-dependent least squares support vector machine inference model, Journal of Civil Engineering and Management 21(6): 679-688. https://doi.org/10.3846/13923730.2014.893906

Cheng, M. Y.; Wibowo, D. K.; Prayogo, D.; Roy, A. F. 2015 b. Predicting productivity loss caused by change orders using the evolutionary fuzzy support vector machine inference model, Journal of Civil Engineering and Management 21(7): 881-892.

https://doi.org/10.3846/13923730.2014.893922

Chou, J. S. 2012. Comparison of multilabel classification models to forecast project dispute resolutions, Expert Systems with Applications 39(11): 10202-10211. https://doi.org/10.1016/j.eswa.2012.02.103

Chou, J. S.; Lin, C. 2012. Predicting disputes in public-private partnership projects: classification and ensemble models, Journal of Computing in Civil Engineering 27(1): 51-60. https://doi.org/10.1061/(ASCE)CP.1943-5487.0000197

Chou, J. S.; Cheng, M. Y.; Wu, Y. W.; Wu, C. C. 2012. Forecasting enterprise resource planning software effort using evolutionary support vector machine inference model, International Journal of Project Management 30(8): 967-977. https://doi.org/10.1016/j.ijproman.2012.02.003

Chou, J. S.; Tsai, C. F.; Lu, Y. H. 2013. Project dispute prediction by hybrid machine learning techniques, Journal of Civil Engineering and Management 19(4): 505-517. https://doi.org/10.3846/13923730.2013.768544

Chou, J. S.; Cheng, M. Y.; Wu, Y. W.; Pham, A. D. 2014. Optimizing parameters of support vector machine using fast messy genetic algorithm for dispute classification, Expert Systems with Applications 41(8): 3955-3964. https://doi.org/10.1016/j.eswa.2013.12.035

Cortes, C.; Vapnik, V. 1995. Support-vector networks, Machine Learning 20(3): 273-297. https://doi.org/10.1007/BF00994018

Dawood, N. N. 1995. An integrated bidding management expert system for the make-to-order precast industry, Construction Management and Economics 13(2): 115-125. https://doi.org/10.1080/01446199500000014

Egemen, M.; Mohamed, A. 2008. SCBMD: a knowledge-based system software for strategically correct bid/no bid and mark-up size decisions, Automation in Construction 17(7): 864-872. https://doi.org/10.1016/j.autcon.2008.02.013

El-Mashaleh, M. S. 2010. Decision to bid or not to bid: a data envelopment analysis approach, Canadian Journal of Civil Engineering 37(1): 37-44. https://doi.org/10.1139/L09-119

El-Mashaleh, M. S. 2013. Empirical framework for making the bid/no-bid decision, Journal of Management in Engineering 29(3): 200-205.

https://doi.org/10.1061/(ASCE)ME.1943-5479.0000147

Hsu, C. W.; Chang, C. C.; Lin, C. J. 2003. A practical guide to support vector classification [online], [cited 10 Oct 2016]. Available from Internet: http://www.csie.ntu.edu.tw/ cjlin/ papers/guide/guide.pdf
Keerthi, S. S.; Lin, C. J. 2003. Asymptotic behaviors of support vector machines with Gaussian kernel, Neural Computation 15(7): 1667-1689.

https://doi.org/10.1162/089976603321891855

Lam, K. C.; Lam, M. C. K.; Wang, D. 2009. Efficacy of using support vector machine in a contractor prequalification decision model, Journal of Computing in Civil Engineering 24(3): 273-280. https://doi.org/10.1061/(ASCE)CP.1943-5487.0000030

Lin, C. T.; Chen, Y. T. 2004. Bid/no-bid decision-making-a fuzzy linguistic approach, International Journal of Project Management 22(7): 585-593. https://doi.org/10.1016/j.ijproman.2004.01.005

Mahfouz, T.; Kandil, A. 2012. Litigation outcome prediction of differing site condition disputes through machine learning models, Journal of Computing in Civil Engineering 26(3): 298-308. https://doi.org/10.1061/(ASCE)CP.1943-5487.0000148

Ravanshadnia, M.; Rajaie, H.; Abbasian, H. R. 2010. Hybrid fuzzy MADM project-selection model for diversified construction companies, Canadian Journal of Civil Engineering 37(8): 1082-1093. https://doi.org/10.1139/L10-048

Sammut, C.; Webb, G. I. (Eds). 2011. Encyclopedia of machine learning. Springer.

Shash, A. A. 1993. Factors considered in tendering decisions by top UK contractors, Construction Management and Economics 11(2): 111-118. https://doi.org/10.1080/01446199300000004

Shastri, V.; Rabelo, L. C.; Onjeyekwe, E.; Vila, J. 1998. Deviceindependent color correction for multimedia applications using neural networks and abductive modeling approaches, Expert Systems 15(2): 110-119. https://doi.org/10.1111/1468-0394.00069

Sonmez, R. 2011. Range estimation of construction costs using neural networks with bootstrap prediction intervals, Expert Systems with Applications 38(8): 9913-9917. https://doi.org/10.1016/j.eswa.2011.02.042

Sonmez, R.; Rowings, J. E. 1998. Construction labor productivity modeling with neural networks, Journal of Construction Engineering and Management 124(6): 498-504.

https://doi.org/10.1061/(ASCE)0733-9364(1998)124:6(498)

Sözgen, B. 2009. Neural network and regression models to decide whether to bid or not to bid for a tender in offshore petroluem platform fabrication industry: MS thesis. Middle East Technical Univ., Ankara, Turkey.

Tserng, H. P.; Lin, G. F.; Tsai, L. K.; Chen, P. C. 2011. An enforced support vector machine model for construction contractor default prediction, Automation in Construction 20(8): 1242-1249. https://doi.org/10.1016/j.autcon.2011.05.007

Vapnik, V. 2000. The nature of statistical learning theory. Springer. https://doi.org/10.1007/978-1-4757-3264-1

Wanous, M.; Boussabaine, A. A.; Lewis, J. 2000. To bid or not to bid: a parametric solution, Construction Management and Economics 18(4): 457-466. https://doi.org/10.1080/01446190050024879

Wanous, M.; Boussabaine, H. A.; Lewis, J. 2003. A neural network bid/no bid model: the case for contractors in Syria, Construction Management and Economics 21(7): 737744. https://doi.org/10.1080/0144619032000093323

Rifat SONMEZ. Associate Professor at the Department of Civil Engineering, of Middle East Technical University. His current research interest includes optimal resource scheduling, machine learning, project management, conceptual cost estimation.

Burak SÖZGEN. Subcontract Coordinator at the Heerema Fabrication Group. His current research interest includes project management, machine learning. 